\title{
Correction to: Molecular Diagnosis of Acute and Chronic Brucellosis in Humans
}

Maryam Dadar, Youcef Shahali, and Gamal Wareth

\section{Correction to: \\ Chapter 10 in: P. K. Arora (ed.), Microbial Technology for the Welfare of Society, Microorganisms for Sustainability 17, https://doi.org/10.1007/978-981-13-8844-6_10}

The chapter was originally published with an additional affiliation for the authors "Maryam Dadar and Youcef Shahali" which has been removed now. The correct affiliation of these authors are "Razi Vaccine and Serum Research Institute (RVSRI), Agricultural Research, Education and Extension Organization (AREEO), Karaj, Iran". 